\title{
GIM and BIM
}

\section{How to Obtain Interoperability Between Geospatial and Building Information Modelling?}

\author{
Stefan Herle ${ }^{1}\left(\mathbb{D} \cdot\right.$ Ralf Becker $^{1} \cdot$ Raymond Wollenberg $^{1} \cdot$ Jörg Blankenbach $^{1}$
}

Received: 22 October 2019 / Accepted: 9 January 2020 / Published online: 4 February 2020

(c) The Author(s) 2020

\begin{abstract}
Geospatial information modelling (GIM) is used for decades to document phenomena of the real world. Visualizing and analysing GIM data are usually accomplished by geographic information system tools. The construction industry, on the other hand, uses usually computer-aided design (CAD) tools to plan buildings. With the introduction of building information modelling (BIM), modelling in CAD was enhanced to the entire life cycle of constructions. BIM and GIM are not independent of each other, e.g. BIM uses geospatial data for planning purposes. However, integrating both is challenging since the modelling methods differ. The paper describes approaches to establish interoperability between models of both domains. A literature review reveals the problems and challenges different researchers tackled to achieve interoperability.
\end{abstract}

Keywords Geospatial information modelling $\cdot$ Building information modelling $\cdot$ BIM $\cdot$ Interoperability $\cdot$ GIM

\section{Zusammenfassung}

GIM und BIM. Die Modellierung von Geodaten (GIM) wird seit Jahrzehnten zur Dokumentation von Phänomenen der realen Welt eingesetzt. Die Visualisierung und die Analyse von GIM-Daten wird in der Regel mit Hilfe geographischer Informationssysteme durchgeführt. Die Bauindustrie verwendet andererseits in der Regel CAD-Werkzeuge (Computer-Aided Design) zur Planung von Gebäuden. Mit der Einführung von Building Information Modeling (BIM) wurde die Modellierung in CAD auf den gesamten Lebenszyklus von Bauwerken ausgeweitet. BIM und GIM sind nicht unabhängig voneinander zu sehen. So nutzt z.B. BIM Geodaten für Planungszwecke. Die Integration beider ist jedoch eine Herausforderung, da die Modellierungsmethoden unterschiedlich sind. Der Artikel beschreibt Ansätze zur Herstellung von Interoperabilität zwischen den Modellen beider Bereiche. Eine Literaturübersicht weist auf die Probleme und Herausforderungen hin, mit denen sich eine ganze Reihe von Fachleuten beschäftigt haben, um Interoperabilität zu erreichen.

Stefan Herle

herle@gia.rwth-aachen.de

Ralf Becker

ralf.becker@gia.rwth-aachen.de

Raymond Wollenberg

raymond.wollenberg@gia.rwth-aachen.de

Jörg Blankenbach

blankenbach@gia.rwth-aachen.de

1 Geodetic Institute and Chair for Computing in Civil Engineering \& Geo Information Systems RWTH Aachen University, Mies-van-der-Rohe-Str. 1, 52074 Aachen, Germany

\section{Abbreviations}

AECO Architecture, Engineering, Construction and Operation

B-Rep Boundary Representation

BIM Building Information Modeling

CAD Computer-Aided Design

CSG Constructed Solid Geometry

EIF European Interoperability Framework

ETL Extraction, Transformation, Load

FEI Framework for Enterprise Interoperability

FM Facility Management

GIM Geospatial Information Modeling

GIS Geographic Information System

GML Geography Markup Language

HTTP Hypertext Transfer Protocol

IFC Industry Foundation Classes 


$\begin{array}{ll}\text { JSON } & \text { JavaScript Object Notation } \\ \text { LCIM } & \text { Level of Conceptual Interoperability Model } \\ \text { LoD } & \text { Level of Detail } \\ \text { LOD } & \text { Level of Development } \\ \text { OGC } & \text { Open Geospatial Consortium } \\ \text { OWL } & \text { Web Ontology Language } \\ \text { RDF } & \text { Resource Description Framework } \\ \text { SRS } & \text { Spatial Reference System } \\ \text { TBS } & \text { Technical Building System } \\ \text { UIM } & \text { Urban Information Modeling } \\ \text { UML } & \text { Unified Modeling Language } \\ \text { URI } & \text { Uniform Resource Identifier } \\ \text { WWW } & \text { World Wide Web } \\ \text { XML } & \text { Extensible Markup Language }\end{array}$

\section{Introduction}

Designing and planing of landscapes, urban areas and buildings have changed dramatically in recent years. The digital transformation of the society, economy, businesses and private life also increasingly affects construction and management activities of humans.

For modelling the environment of large areas, geographic information systems (GISs) have already been productively used since the 1970s (Bill 2016). With the introduction of the third spatial dimension in geospatial data, novel applications and analysis tools such as noise transmission or flooding simulations can be conducted. This development is especially driven and fostered by the evolution of data acquisition methods and automated workflows, which can be accomplished with reduced costs through increasing computing power or innovative sensor technology.

Models that cope with geometric data on a building level are traditionally handled by computer-aided design (CAD) software, or since a couple of years by the method and associated tools of building information modelling (BIM). BIM describes the consistent and integrated modelling of all data with respect to a specific construction and during its life cycle (see Sect. 2.1).

However, BIM is not decoupled from geospatial data and models. For optimized planning, construction and operation, both modelling views are complementary. This circumstance forces developers to integrate BIM models in a broader concept of geospatial models. On the other hand, usually geospatial data are also required in BIM. During the planning phase of new constructions, the planner needs to consult geospatial data such as land register data, city or landscape models as well as digital terrain models. Due to their different nature and modelling approaches, the integration is, however, a difficult task. Several researchers have tried to tackle this problem by various approaches. Arroyo Ohori et al. (2018) started the GeoBIM project to bridge the gap between methods and models of the geospatial domain and BIM. They found that automated processing of complex architectural models is very difficult, so that a complete working interface for GIS and BIM integration could not be developed within the time frame of the project. van Berlo and de Laat (2011) developed an extension for CityGML, which they also called GeoBIM, to integrate semantic BIM data into a GIS context. Hijazi et al. (2018) investigated the integration of data and tools from the BIM and the urban information modelling (UIM) domain. In this context, the term UIM describes a semantic modelling method, that is similar to the BIM method, but is used on a larger scale for representing relevant entities of urban areas (e.g. buildings or roads in city models). Kumar et al. (2019) inspected the LandInfra standard and its capabilities to bridge BIM and GIS. They found that LandInfra is situated at the intersection of BIM and GIS. But it is rather inspired by modelling standards of 3D GIS since in the BIM world, objects are modelled in a different way.

In this paper, we investigate the different approaches to integrate models of the two domains: on the one hand, BIM for modelling of buildings and constructions and, on the other hand, modelling of geospatial data, how it is used by GIS. Since GIS refers rather to a tool than to a geospatial modelling approach, we use the term geospatial information modelling (GIM) as a similar concept to BIM but in the geospatial domain (see Sect. 3). The integration of BIM and GIM models can be accomplished through four different approaches of interoperability: first, the transformation back and forth between the different formats of both modelling methods; second, linked models; third, unified models; finally, integrated models. After giving a more detailed insight into the BIM method and comparing its modelling capabilities and approaches with the GIM method, we illustrate the efforts of several researchers in establishing interoperability using the mentioned models.

\section{Building Information Modelling (BIM)}

Building information modelling (BIM) is a modern cooperative approach in the architecture, engineering, construction and operation (AECO) industry based on digital models of a specific building or construction. The German Federal Ministry of Transport and Digital Infrastructure (BMVI 2015) defines BIM as follows:

"Building Information Modelling means a collaborative work method that creates and uses digital models of an asset as a basis for the consistent generation and management of information and data relevant to the asset's life cycle as well as for the sharing or passing on of such information and data between the par- 
Fig. 1 Left: BIM and the trades in construction. Right: BIM in the building cycle

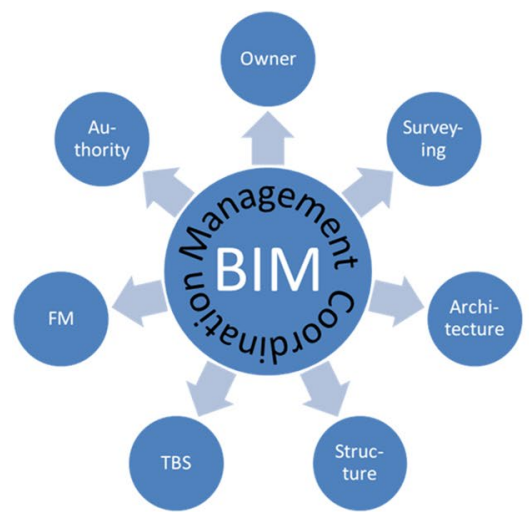

ticipants for further processing by way of transparent communication."

The British BIM Industry Working Group distinguishes further between different maturity levels of BIM. While level 0 describes solely the utilization of 2D CAD software to create paper drawings, level 1 extends it to the modelling of geometries in 3D as well as file-based collaboration. Level 2 specifies the use of BIM tools with attached data. Ultimately, level 3 covers a fully integrated BIM with standardized formats and interfaces as well as a complete life cycle management (BIS 2011). In this ultimate stage, information and data about the building during its entire life cycle are collected in the digital model in a cloud-based environment. Building information is transparently shared and managed between the stakeholders of the specific phase in the life cycle. Thus, the central component of the BIM method is the shared database, which stores a digital, all-encompassing and consistent building model. As long as the stakeholder has the rights, he or she is able to access and update the model using defined interfaces and procedures, which facilitates cooperative work (see Fig. 1 on the left). Since the life cycle of a building starts with planning phases (see Fig. 1 on the right), in most cases, the digital model is created before the construction execution starts. It affects several phases with different information in the life cycle. Hence, besides the 3D geometry and construction information, technical and functional data as well as aspects of time and cost management are stored in the model.

\subsection{Life Cycle Phases in BIM}

The life cycle of a building starts with the pre-design and conceptual planning. A lot of information is collected from different sources and integrated into a newly created BIM model. Also geospatial datasets are already consulted in this early phase. In the planning and design phase, the building construction is modelled using a BIM software. The model is compiled using building components with $3 \mathrm{D}$ geometry and attributive information. Based on the model, slices and construction plans can be derived, area, volume and quantity measures can be calculated, and costing and time management can be conducted. Since the building exists solely as a digital model, different simulations and variants can be analysed. Coordination of various planners or clash detection between different aspect models is facilitated. These tasks also interact with information about the surrounding environment; thus, geospatial data must be integrated here as well (e.g. Barazzetti and Banfi 2017).

In the construction phase, the BIM model is used as a guideline. Based on the model, construction plans, management as well as logistics are compiled and executed. Information is added to the model to document construction progress and controlling. Furthermore, using the digital model can support and improve construction defect management. Additionally, commissioning and handover can be facilitated by accounting of construction services using the as-designed BIM model and an as-built-documentation of the final building. The as-built-documentation must be derived from the constructed building on-site by suitable measurement techniques (e.g. laser scanning). It can be consulted to compare with the planned model.

Subsequently, operation of the building benefits from an updated BIM model (as-is-documentation). This includes (computer-aided) facility management (CAFM) or conservation management. Finally, an up-to-date BIM model also improves demolition or refurbishment of the building, e.g. by supporting selective disassembly.

\subsection{Semantic Modelling in BIM}

The semantic modelling in BIM covers several properties and information during the different life cycle phases. This includes costs, timetables and simulations. However, very important information is stored in the geometry and the construction information of the building model. Contrary to CAD, BIM uses an object-oriented approach together with semantic data models to characterize the building 
components. Each component, e.g. wall, door or beam, is modelled as an object with different properties. The geometry of the object usually is described by a constructed solid geometry (CSG), which is an implicit method to construct complex surfaces or objects using Boolean operators to combine simpler objects. Furthermore, relations to other construction components (neighbourhood, groupings, etc.), semantics, attribute data and visualization information are included for each building part. Usually, a BIM model consists of various aspect models, which are compiled by each involved domain on its own. For instance, an architectural model designed by an architect has no information about the technical equipment, which is rather documented in a specific technical building equipment model. The aggregation of all these models results in a coordination model.

\subsection{Industry Foundation Classes (IFC) - A BIM Model Encoding}

Several data models and encodings for BIM exist. The free and open IFC schema is used for storing and exchanging BIM models. It is vendor independent and further developed by buildingSMART international. While version 4.0 was released as an ISO standard in 2013, the most recent version is 4.1.0.0 (BuildingSMART 2018). IFC can be used to describe the project structure, the building components with their geometric and attributive properties as well as the relations between them. Figure 2 illustrates as an example, a subset of the IFC data model and a closeup to IfcWall for modelling a wall. Usually encoded in the STEP format, IFC supports also other formats, such as Extensible Markup Language (XML) or prospectively JavaScript Object Notation (JSON). The models can be transmitted over web services, imported/exported in files, or managed in centralized or linked databases.

The standardization process of the IFC encoding is ongoing. Initially, only considered for BIM in building constructions, the method and, thus, also the IFC encoding, evolved into other civil engineering industries such as infrastructural management (bridges, roads, rails and maritime). Hence, the IFC version 4.1.0.0 introduced new standards for infrastructure constructions. The first full extension for infrastructure is planned to be reached with version 5.0.

\section{Differences Between BIM and GIM}

The planning of new buildings or infrastructure constructions usually requires geospatial data. This holds, e.g. for city models, digital terrain models or environmental data. Different variants of planned models can be rendered in city models in GIS to perceive the impact in an overall image. For instance, shadow and visibility analysis as well as simulations of emissions can be executed (e.g. Rafiee et al. 2014). The results can then be used to refine the building model. Also in the subsequent phases of the BIM life cycle, geospatial data enhance the BIM model. On the other hand, BIM models can also be integrated into, e.g. city models, after the construction is realized in the real world.

For comparing BIM and modelling in the geospatial domain, we introduce the term Geospatial Information Modelling (GIM). We define it as follows:

"Geospatial Information Modelling (GIM) denotes the digital modelling method of space-related phenomena

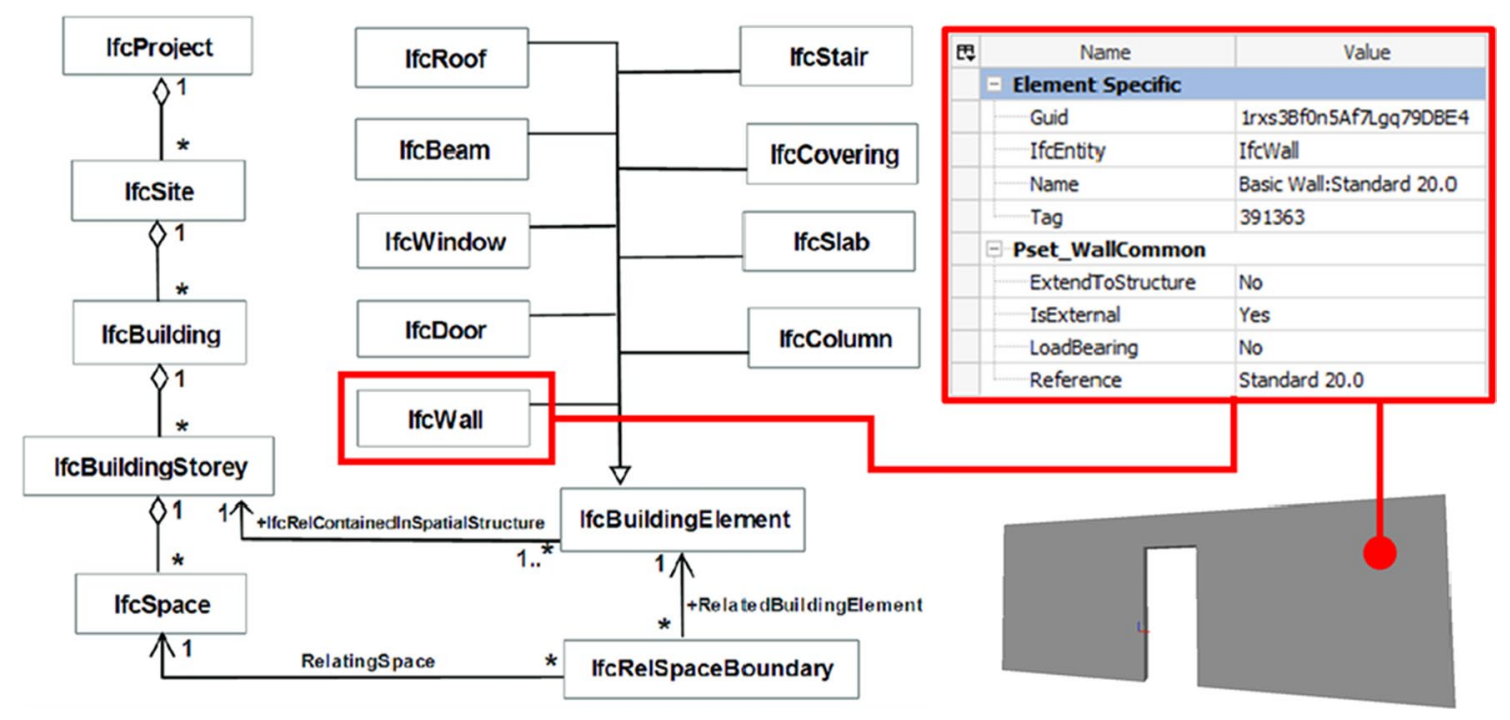

Fig. 2 Coarse section of IFC building model with wall properties (diagram source: Atazadeh et al. 2017) 


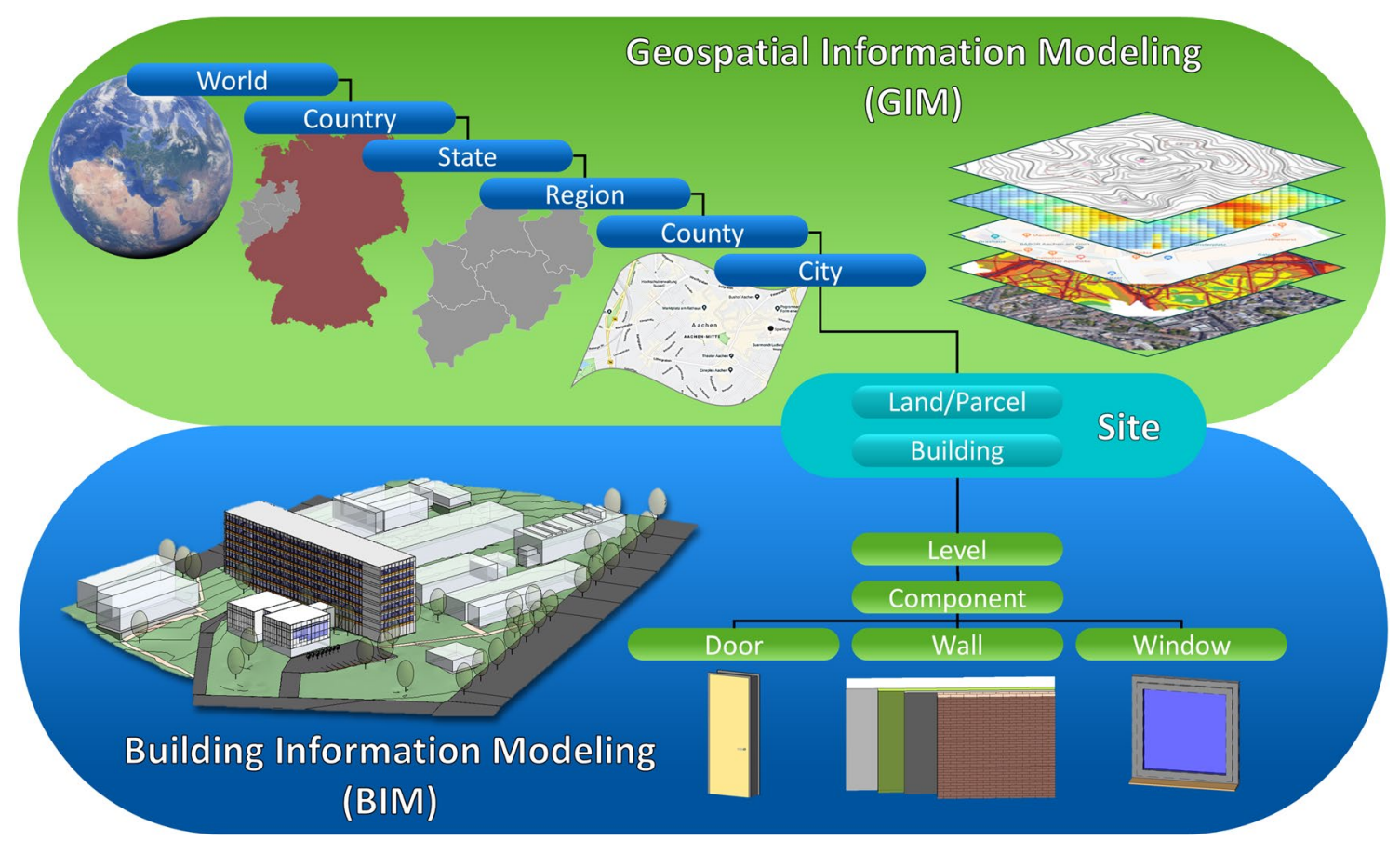

Fig. 3 BIM and GIM and their common objects (adapted from Hutsell and Bush 2016)

of the real world. It is characterized by multidimensional descriptions of geospatial features by location and orientation in Spatial Reference System (SRS), raster/vector geometry and topology, attribute data and time. Thus, GIM is used as a digital documentation of real world states and can be applied to a variety of spatially related questions."

BIM and GIM are complementary as Fig. 3 suggests. The common objects in both modelling worlds are mostly on the site and building level. Every geospatial feature with a larger extent is rather considered to be part of GIM models, while especially detailed building components are part of the BIM world.

Although having similar intersecting objects in their modelling, the exchange of data and models between the BIM and the GIM methods is not trivial. This is mainly due to differences in purpose and perspective of the two modelling approaches (Becker et al. 2017). The perspectives and origins have direct impact on the comparability and interoperability. The differences and similarities are described in the following sections.

\subsection{Modelling and Geometry}

While GIM deals with modelling geospatial features of the real world on a small scale, BIM aims at modelling a building or construction in a detailed view, which is either planned to be realized in the real world in the future or is already built. The BIM perspective is mainly shaped by its origin for being a tool for planning. In BIM, geometries are usually defined as CSG. Volumetric bodies such as cuboids, cylinders or cones are combined using Boolean operators to form a specific building component. In GIM, the modelling of geometries differs from that approach. GIM wants to represent the real world like it is perceived and observed. Hence, digital models focus on the surface of geospatial features. Unlike BIM, in GIM, the shapes of geometries are described explicitly by their nodes, edges and surfaces, characterized by coordinates. The so-called boundary representation (B-Rep) is one of the most used models in $3 \mathrm{D}$ to define geometries by their surfaces. CityGML is one of the standards issued by the Open Geospatial Consortium (OGC) that are used to encode city models with B-Rep geometries (Gröger et al. 2012).

\subsection{Scope and Coordinate System}

BIM focuses on single construction sites such as a building or an infrastructure object. The structure of the building with different components and technical equipment are modelled. Hence, a local Cartesian coordinate system using the ordinal building axes for orientation and an appropriate measure facilitate the modelling.

As mentioned, GIM models are rather used for a smallscale projection of the real world. This includes applications such as land, environment or network information systems. Also extensive planning of, e.g. landscapes, urban areas or 
road networks can be accomplished by GIM methods and associated tools. For these kinds of applications, a local Cartesian coordinate system is not sufficient. Therefore, SRSs such as ETRS89 with UTM are utilized to project the surface of the Earth.

\subsection{Modelling Details and Accuracy}

In the BIM method, the concept and application of Level of Development (LOD) are utilized to describe the requirements of the details in the model during the planning phases. While in the pre-design phase, the level of details of the geometry is secondary, the execution planning requires more details. Thus, the modelling details of geometry and semantic information in a BIM model evolve during its usage in the life cycle. For instance, in the construction phase, the LOD requires the geometric and other information necessary for actual fabrication.

In GIM, on the other hand, geospatial features of the real world are captured by surveying. Thus, the accuracy depends on the measurement procedure of the utilized surveying instruments. So, while the accuracy is given by the measurement and the abstraction of the real world, depth of details in GIM models, e.g. in CityGML, can be specified by the level of detail (LoD) concept. For instance, in LoD 1, buildings are represented by block models only, usually through extruded footprints. In $\operatorname{LoD} 3$, a building is a detailed architectural model with, e.g. roof structures, walls and windows. Further, LoD 4 also considers indoor structures such as rooms or building installations. The LoD concept is based on the principles of generalization, and, thus, can be used to describe the level of graphical details that are rendered in, e.g. a 3D viewer. Since LOD in the BIM and LoD in GIM method describe different concepts, both terms, LOD and LoD, should not be used interchangeably.

\section{Interoperability Between BIM and GIM}

As pointed out, BIM and GIM technologies have a different origin and come from different domains. While the BIM method is originally used in planning tools for constructing buildings and other structures, GIM is used to model geospatial features of the real world with an applicationdependent accuracy. Both concepts are already matured and used by various industries in a productive mode. However, although BIM and GIM have different backgrounds, they depend on each other or each other's data during several life cycle phases. Thus, for data integration purposes, interoperability between the data models of GIM and BIM is desired to exchange data or to achieve an overall model from both perspectives.

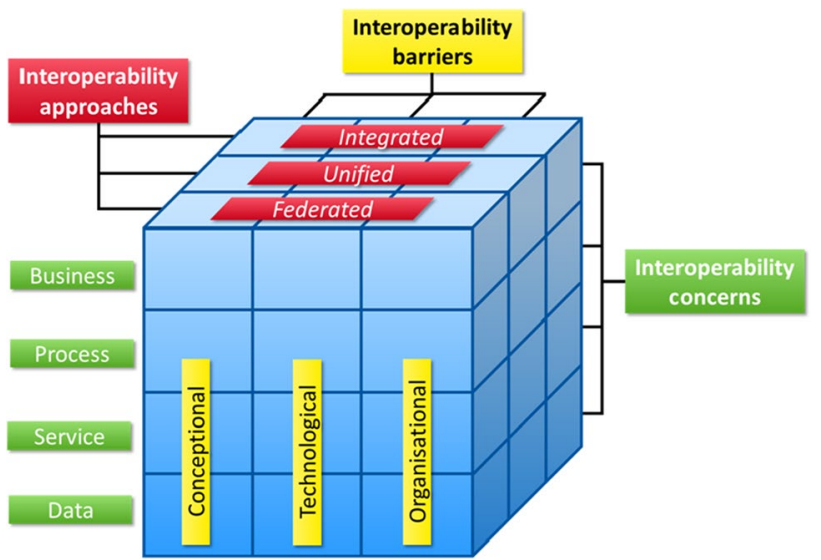

Fig. 4 Framework for enterprise interoperability (FEI) (adapted from ISO/TC 184 2012)

First, this section introduces the concept of interoperability, several levels of interoperability and approaches to ensure or to establish interoperability between systems. Second, different approaches of interoperability between BIM and GIM models are presented in Sect. 4.2.

\subsection{Interoperability}

According to the IEEE 610 working group (1990), interoperability is

"the ability of two or more systems or components to exchange information and to use the information that has been exchanged."

Interoperability is not only a technical issue but involves also other dimensions. The ISO standard 11354-1 (ISO/TC 184 2012) defines a model-driven interoperability (MDI) framework for enterprise interoperability, the so-called framework for enterprise interoperability (FEI). In the framework, the concepts of interoperability concerns, barriers and approaches are contextualized. They can be depicted in a cube with three dimensions (see Fig. 4).

In FEI, the interoperability concerns identify the area of interoperation that may take place at various levels of the enterprise, namely data, service, processes and business. Interoperability barriers describe various identified obstacles to interoperability in the categories conceptual, technological and organizational. Interoperability approaches indicate solutions how barriers can be removed. This includes first an integrated approach, where a common format is found for all models. The unified approach has also a common format for the models but solely on meta-level. Finally, the federated approach does not support common formats for models or meta-models: each single model is still used but mapping rules are defined between them. 


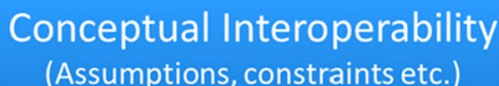

(Assumptions, constraints etc.)

L5

L4

L3

L2

L1

LO

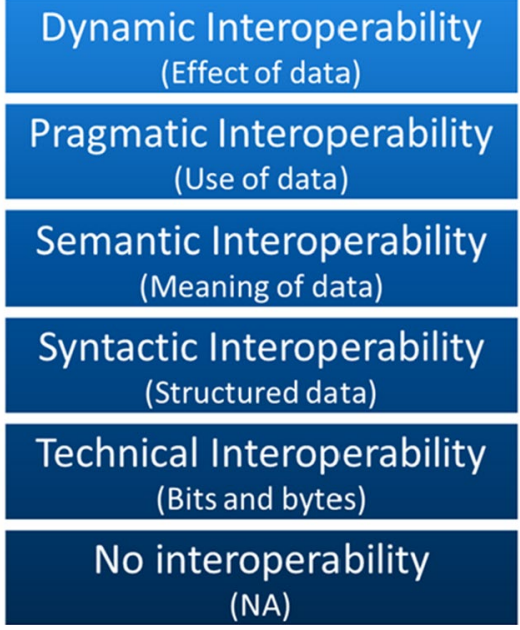

Fig. 5 Level of conceptual interoperability model (LCIM) (adapted from Wang et al. 2009)

When addressing interoperability concerns with these approaches, different barriers have to be overcome. These barriers are often built upon each other. For instance, before addressing conceptual barriers of two systems, technological issues have to be solved. Therefore, a certain sequence of solving interoperability barriers between systems should be followed. The level of conceptual interoperability model (LCIM) introduces such an order. It is a framework originally proposed by Tolk and Muguira (2003) and further developed by other authors (see Fig. 5). The model consists of seven levels from "no interoperability" (L0), in which no connection between two or more systems is established, to "conceptual interoperability" (L6), which describes systems with a common conceptual model. Technical interoperability (L1) describes the ability to produce and consume data in exchange with external systems, e.g. using network connection standards such as TCP/IP. Syntactic interoperability (L2) is a set of agreed-to formats that are supported by the technical solution levels, e.g. XML or SOAP. At semantic interoperability (L3), the participating systems agree on a set of terms and terminology. Further levels include sharing of terms and methods (L4), the means of producing and consuming the definitions of meaning (L5) and, ultimately, a shared understanding of the conceptual model (L6) (Wang et al. 2009).

Other interoperability models are similar to the LCIM model. For instance, the European Interoperability Framework (EIF) specifies a model with four layers, which is applied to digital public services within the European Union (EU) (European Commission 2017).

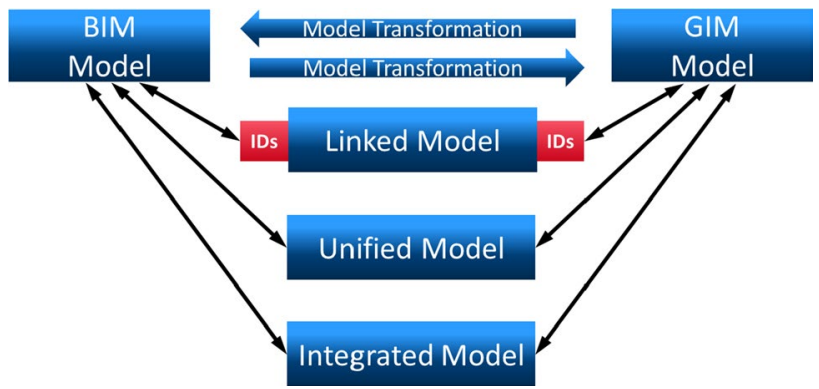

Fig. 6 Interoperability approaches for integrating BIM and GIM (extension of Hijazi and Donaubauer 2017 )

\subsection{Solutions for BIM-GIM Interoperability}

Interoperability barriers between BIM and GIM can be found especially for data and service concerns at the conceptual and technological level in the FEI model. For instance, the concepts of modelling spatial referencing differ conceptually from each other. Whilst GIM utilizes the spatial referencing by absolute coordinates defined in ISO/TC 211 (2014), BIM uses coordinates in a local Cartesian coordinate system. Technologically, GIM uses-besides raster datavector geometry (for example, B-Rep models), but geometries in BIM are often described by the CSG.

Basically, the interoperability approaches defined by the FEI can be applied to the BIM-GIM integration problem. Since technical and syntactic interoperability is already given by encoding in bits and bytes and by different formats, the consecutive goal is to achieve a semantic interoperability (L3 in LCIM), so that terms, terminology and notions are comparable from both worlds. The interoperability aims at semantic level constitutes in a shared data model. Hijazi and Donaubauer (2017) distinguish between three approaches to achieve semantic interoperability: model transformation, linked models and unified models. While linked and unified models correspond to the federated and unified approaches in the FEI standard, model transformation describes the process of transferring a source model into a target model by transformation, conversion and mapping rules. However, the integrated model approach of the FEI model is missing in their model of achieving semantic interoperability between BIM and GIM models. In our updated model (see Fig. 6), we introduce integrated models as a fourth option to ensure interoperability between BIM and GIM models. By applying integrated models, the highest level of interoperability could be ensured.

\subsubsection{Model Transformation}

Model transformation between BIM and GIM models can be achieved by applying transformation to the data using a set of mapping and conversion rules. This is often accomplished 
with the help of extraction, transformation, load (ETL) tools. Several commercial software tools for these transformation processes are available. Transformation is possible in both directions: IFC data can be transformed to CityGML and vice versa. This approach has some advantages: both models stay independently without further standardization efforts, and because of the direct transformation, it can be done quite easily with a high user acceptance. However, because of the different nature of BIM and GIM, it also has some major drawbacks, which can be essential in applications. Both models own intrinsically different aims and modelling details, so that information loss and gaps always occur when applying model transformation. A mapping procedure between various attributes in the models is sometimes not possible or can be accomplished in a limited fashion. Especially the geometric transformation proves to be problematic since in BIM and GIM geometries are modelled in a different way (planar vs. volumetric). This may lead to ambiguities, which have to be resolved, sometimes manually. In the literature, a lot of model transformation efforts can be found to integrate BIM into GIM models (van Berlo and de Laat 2011; Deng et al. 2016; Ohori et al. 2017; Sani and Rahman 2018; Knoth et al. 2019; Zadeh et al. 2019). As expected, they run especially into problems regarding the geometric transformation due to the different modelling approach of geometries in BIM and GIM.

\subsubsection{Linked Models}

Linked models correspond to the federated interoperability approach in the FEI standard. The data of the models stay independent of each other and are stored in their original model. A link model (sometimes multi-model) is introduced to interconnect the subject-specific models, e.g. by identifiers (IDs). The linkage can be established either on data level using technologies of the Semantic Web or on service level, e.g. through web services. Common technologies of the World Wide Web (WWW) such as Hypertext Transfer Protocol (HTTP), Uniform Resource Identifiers (URIs) or XML are utilized to create interoperable data models, which can be accessed through networks. This setup provides technical and syntactic interoperability according to the LCIM model. To achieve semantic interoperability, a Semantic Web technology stack needs to be used. Here, the resource description framework (RDF) can be applied to express data, information and knowledge in form of statements. A statement in RDF is codified as a semantic triple that has the form of a subject-predicate-object expression. Every part of a RDF triple can be addressed via unique URIs. A RDF triple indicates exactly one relationship between a subject and an object named by the predicate. To obtain pragmatic interoperability, the Web Ontology Language (OWL) may extend the RDF triples. OWL allows to represent conceptual schemas with rich vocabulary to add semantics and context. In combination, reasoning and inference about data can be accomplished. This can be useful in applications, in which semantic indoor and outdoor information are important, e.g. in an evacuation planning scenario (Hor et al. 2016).

This approach has some advantages such as the data stay in its original structure. Further, scalability and case-dependent adaptability can be obtained. However, drawbacks are the required intelligent implementation and the necessary maintenance of the linked model, especially if the original models are updated.

For instance, Hor et al. (2016) developed an approach to integrate BIM and GIM using semantic web technologies and RDF graphs. Their Integrated Geospatial Information Model (IGIM) offers access to GIM and BIM datasets through a RDF-directed graph. To achieve this, IFC and CityGML are first translated into IFC-RDF, respectively, GIS-RDF graphs and subsequently integrated at the semantic level. Vilgertshofer et al. (2017) also applied semantic web technology (RDF and OWL) to link IFC and CityGML. They also integrated the IFC Tunnel schema with latest infrastructure developments of buildingSMART. Further approaches can be found in, e.g. Karan et al. (2016).

\subsubsection{Unified Models}

The unified model approach transforms BIM and GIM models into one superior single model, which integrates common details from both worlds. This ensures that for these details, no information loss occurs, which is the main advantage of this approach. However, defining a unified model requires additional efforts. The harmonization and standardization of a single model need a lot of coordination between the disciplines, and the acceptance of the resulting model is not guaranteed, especially, if the domain-specific models are more expressive. The risk lies in redundant data storage in different models. Software products may be forced to support multiple models because of its low acceptance.

Different researchers try to implement unified models for integrating BIM and GIM. El-Mekawy et al. (2012) implement a unified building model (UBM) that encapsulates the IFC as well as the CityGML encoding. This prevents for direct transformation and also loss of information is avoided. The approach is validated through use cases. The authors note that other case studies are required to advance the set of constraints and enrichment functions. Besides scientific research, there has been some standardization effort from different institutions.

LandInfra (land and infrastructure) (Scarponcini 2016) as a successor to LandXML (LandXML and U.S. Federal Highway Administration (IHSDM) 2008) is a new open standard issued by the OGC in conjunction with the buildingSMART Infrastructure IfcAlignment project team. The 
conceptual data model can be used to represent land and civil engineering infrastructure features. It was designed to bridge GIM and BIM by integrating concepts from the different domains, especially it has overlaps with CityGML and IFC. LandInfra has a conceptual model specified in Unified Modelling Language (UML) and a Geography Markup Language (GML) encoding called InfraGML, which corresponds to the concept of CityGML. But at the same time, parts are based on the buildingSMART IFC Alignment 1.0 standard. However, Kumar et al. (2019) found that a lot of BIM-GIM integration problems cannot be solved with the standard. LandInfra is much closer to 3D GIM models than to BIM models. Thus, interoperability to BIM formats is limited. Additionally, LandInfra is not extendable and cannot be adjusted to further or updated formats.

\subsubsection{Integrated Models}

A fully integrated model for BIM and GIM implies that all aspects of both models are integrated into one model. The resulting single model represents all details from both perspectives. It should be standardized to achieve maximal interoperability. Domain specific models such as IFC or CityGML become unnecessary since every use-case can be represented by the integrated model. This is different from the unified model, in which solely the common information is stored. The LandInfra standard is a step towards such an integrated model but, as mentioned, represents rather a unified model. Other approaches or initiatives are currently not being pursued. The question arises if such a model is to seek in the long run. However, the integrated model approach promises the highest interoperability, but is the most effortful approach and, simultaneously, inflexible towards modifications of a specific domain.

\section{Conclusion}

Digital information of the built environment gains importance, especially in civil engineering through the transformation to digital planning, constructing and operating. Synergies and complementarities between GIM and BIM models and data should be realized for optimal workflows in practice, in particular for larger construction projects such as in the field of infrastructure.

However, BIM and GIM have been developed in the context of two previously distinct domains. Nevertheless, often data from GIM must be integrated into BIM models, especially to enhance planning and execution of constructions. Similarly, GIM models of the geospatial domain such as landscape models need the integration of BIM models to update the digital representation of the real-world state. Thus, interoperability between both models is desirable.
However, it turns out that achieving interoperability between BIM and GIM models is difficult. Due to different paradigms in modelling, the transfer of data is not trivial. For instance, the often-applied IFC encoding in BIM and the CityGML encoding in GIM use different types of modelling geometries; while geometries in IFC are specified in parametric form, in CityGML, solely visible geometries of the constructed world are described explicitly by points, edges and surfaces.

Initial approaches to establish interoperability between GIM and BIM exist. These include mainly methods using schema transformation. However, a solution to achieve consistent and continuous interoperability is not found yet. In this paper, different approaches were discussed to achieve interoperability between GIM and BIM models. FEI defines three interoperability approaches: federated (or linked), unified and integrated models. However, the most simple approach is to transform the models using a mapping and conversion rule set. Similarly in linked models, these rules are used together with semantic web technologies such as RDF to establish interoperability between the two models. The approach introduces links to interconnect the different data models and its parameters. Unified models try to establish one superior single model that integrates common details of both worlds. Theoretically, for these details, no information loss occurs but harmonization and standardization are very effortful. The highest level of interoperability can be achieved by integrated models; however, an integrated model has not been established so far.

A unified or even integrated model is far from being introduced, and it is questionable if such a model is favourable after all. Besides the need for improved coordination of standardization activities to establish interoperability, practical experience must clarify first which domain model should be used for which issue. Currently, the IFC standard is growing fast, but the question arises whether every aspect should be covered by IFC. We know from the GIM perspective, however, that such an uber standard is rather impractical. Since transforming between BIM and GIM models back and forth is in some cases inconvenient and impractical, we conclude that linking the models of the two domains in an intelligent and sophisticated way should get more attention in practice to establish interoperability. This, however, requires strengthening of coordination and standardization activities between both domains.

Acknowledgements Open Access funding provided by Projekt DEAL.

Open Access This article is licensed under a Creative Commons Attribution 4.0 International License, which permits use, sharing, adaptation, distribution and reproduction in any medium or format, as long as you give appropriate credit to the original author(s) and the source, provide a link to the Creative Commons licence, and indicate if changes were made. The images or other third party material in this article are 
included in the article's Creative Commons licence, unless indicated otherwise in a credit line to the material. If material is not included in the article's Creative Commons licence and your intended use is not permitted by statutory regulation or exceeds the permitted use, you will need to obtain permission directly from the copyright holder. To view a copy of this licence, visit http://creativecommons.org/licenses/by/4.0/.

\section{References}

Arroyo Ohori K, Diakité A, Krijnen T, Ledoux H, Stoter J (2018) Processing BIM and GIS models in practice: experiences and recommendations from a GeoBIM project in The Netherlands. ISPRS Int J Geo-Inf 7(8):311. https://doi.org/10.3390/ijgi7080311

Atazadeh B, Rajabifard A, Kalantari M (2017) Assessing performance of three BIM-based views of buildings for communication and management of vertically stratified legal interests. ISPRS Int J Geo-Inf 6(7):1-22. https://doi.org/10.3390/ijgi6070198

Barazzetti L, Banfi F (2017) BIM and GIS: when parametric modeling meets geospatial data. ISPRS Ann Photogramm Remote Sens Spatial Inf Sci 4(5W1):1-8, https://doi.org/10.5194/isprs-annal s-IV-5-W1-1-2017

Becker R, Kaden R, Blankenbach JM (2017) Building Information Modeling (BIM) - neue Perspektiven für Geodäten. Building Information Modeling (BIM) - new perspectives for Geodesists. GISbusiness 5:50-57

Bill R (2016) Grundlagen der Geo-Informationssysteme, 6th edn. Wichmann, Berlin

BIS (2011) A report for the Government Construction Client Group. Strategy Paper, Building Information Modelling (BIM) Working Party

BMVI (2015) Road map for digital design and construction. Tech. rep, Federal Ministry of Transport and Digital Infrastructure, Berlin

BuildingSMART (2018) Industry Foundation Standard -Version 4.1.0.0. buildingSMART

Deng Y, Cheng JC, Anumba C (2016) Mapping between BIM and 3D GIS in different levels of detail using schema mediation and instance comparison. Autom Constr 67:1-21. https://doi. org/10.1016/j.autcon.2016.03.006

El-Mekawy M, Östman A, Hijazi I (2012) A unified building model for 3D urban GIS. ISPRS Int J Geo-Inf 1(2):120-145. https://doi. org/10.3390/ijgi1020120

Commission European (2017) New European Interoperability Framework-Promoting seamless services and data flows for European public administrations. Publications Office of the European Union, Luxembourg. https://doi.org/10.2799/78681

Gröger G, Kolbe TH, Nagel C, Häfele KH (2012) OGC City Geography Markup Language (CityGML) Encoding Standard. OGC 12-019 2.0.0:344. https://portal.opengeospatial.org/files/?artif act_id $=47842$

Hijazi I, Donaubauer A (2017) Integration of building and urban information modeling - opportunities and integration approaches. In: Kolbe TH, Bill R, Donaubauer A (eds) Geoinformationssysteme 2017 - Beiträge zur 4. Wichmann, Münchner GI-Runde, pp 42-56

Hijazi I, Donaubauer A, Kolbe T (2018) BIM-GIS Integration as dedicated and independent course for geoinformatics students: merits, challenges, and ways forward. ISPRS Int J Geo-Inf 7(8):319. https ://doi.org/10.3390/ijgi7080319

Hor AH, Jadidi A, Sohn G (2016) BIM-GIS integrated geospatial information model using semantic Web and RDF graphs. ISPRS Ann Photogramm Remote Sens Spatial Inf Sci 3(July):73-79. https:// doi.org/10.5194/isprs-annals-III-4-73-2016
Hutsell S, Bush L (2016) Integrated data capture, BIM, CIM, GIS, and $\mathrm{CAD}$ - owner and industry perspectives on products, processes and policies for informed decision making. In: SPAR 3D expo and conference

IEEE 610 working group (1990) IEEE standard glossary of software engineering terminology. IEEE Standard 610.12-199, https://doi. org/10.1109/IEEESTD.1990.101064. http://ieeexplore.ieee.org/ xpls/abs_all.jsp?arnumber $=159342$

ISO/TC 184 (2012) Advanced automation technologies and their applications-requirements for establishing manufacturing enterprise process interoperability-part 1: Framework for enterprise interoperability. ISO Standard 11354-1

ISO/TC 211 (2014) Geographic information-metadata-part 1: fundamentals. ISO Standard 19115-1:2014

Karan EP, Irizarry J, Haymaker J (2016) BIM and GIS integration and interoperability based on semantic web technology. J Comput Civ Eng. https://doi.org/10.1061/(ASCE)CP.1943-5487.0000519

Knoth L, Mittlböck M, Vockner B, Andorfer M, Atzl C (2019) Buildings in GI: How to deal with building models in the GIS domain. Trans GIS 23(3):435-449. https://doi.org/10.1111/tgis.12541

Kumar K, Labetski A, Arroyo Ohori K, Ledoux H, Stoter J (2019) The LandInfra standard and its role in solving the BIM-GIS quagmire. Open Geospatial Data Softw Stand 4(5):1-16

LandXML, US Federal Highway Administration (IHSDM) (2008) LandXML. http://www.landxml.org/

Ohori KA, Biljecki F, Diakité A, Krijnen T, Ledoux H, Stoter J (2017) Towards an integration of GIS and BIM data : what are the geometric and topological issues? In: 12th 3D Geoinfo conference, ISPRS annals of the photogrammetry, remote sensing and spatial information sciences, ISPRS, 26-27 October, Melbourne, Australia, https://doi.org/10.5194/isprs-annals-IV-4-W5-1-2017

Rafiee A, Dias E, Fruijtier S, Scholten H (2014) From BIM to geoanalysis: view coverage and shadow analysis by BIM/GIS integration. Procedia Environ Sci 22:397-402. https://doi.org/10.1016/j. proenv.2014.11.037

Sani MJ, Rahman AA (2018) GIS and BIM integration at data level: a review. Int Arch Photogramm Remote Sens Spatial Inf Sci ISPRS Archives 42(4/W9):299-306. https://doi.org/10.5194/isprs-archi ves-XLII-4-W9-299-2018

Scarponcini P (2016) OGC® land and infrastructure conceptual model standard (LandInfra). 15-111r1

Tolk A, Muguira J (2003) The levels of conceptual interoperability model. Fall simulation interoperability workshop, september 2003. Orlando, Florida, pp 1-9

van Berlo L, de Laat R (2011) Integration of BIM and GIS: The Development of the CityGML GeoBIM Extension. In: Kolbe TH, König G, Nagel C (eds) Advances in 3D Geo-Information Sciences, Springer-Verlag, Berlin, Heidelberg, pp 211-225, https://doi. org/10.1007/978-3-642-12670-313

Vilgertshofer S, Amann J, Willenborg B, Borrmann A, Kolbe T (2017) Linking BIM and GIS models in infrastructure by example of IFC and CityGML. In: ASCE international workshop on computing in civil engineering

Wang W, Tolk A, Wang W (2009) The levels of conceptual interoperability model: applying systems engineering principles to $M \& S$. In: Spring simulation multiconference 2009 -co-located with the 2009 SISO spring simulation interoperability workshop, pp 1-9. https://doi.org/10.1145/1639809.1655398

Zadeh PA, Wei L, Dee A, Pottinger R, Staub-French S (2019) BimCityGML data integration for modern urban challenges. J Inf Technol Construct 24:318-340 